\title{
A EDUCAÇÃO AMBIENTAL COMO FORMA DE DESPERTAR VOCAÇÕES PARA A CARREIRA DOCENTE EM GEOGRAFIA EM UMA TURMA DO SEGUNDO ANO DO ENSINO MÉDIO DA ESCOLA OLINTO VICTOR-PE
}

\section{ENVIRONMENTAL EDUCATION AS A WAY TO AWAKEN VOCATIONS FOR THE TEACHING CAREER IN GEOGRAPHY IN OLINTO VICTOR SCHOOL}

Jederson da Silva Rocha ${ }^{1}$; Cláudia dos Santos Xavier²; Jacielly Tatiana da Silva Leocadio $^{3}$; Wallace Matheus Aquino de Santana ${ }^{4}$; Ana Paula Torres de Queiroz ${ }^{5}$.

\section{INTRODUÇÃO}

No cenário da educação brasileira é facilmente notável a desvalorização da profissão docente, por parte do Estado, o que implica no distanciamento de interesse de alunos concluintes do ensino médio para os cursos de licenciatura, onde a partir disso, a falta de profissionais de educação para algumas áreas disciplinares dos últimos anos do Ensino Médio nas escolas do Brasil, tornou-se uma realidade

Todo esse contexto induz o surgimento de inúmeras indagações a respeito do ocorrido e, contudo, vêm sendo objeto de discussão tanto em artigos acadêmicos, como na mídia, dada sua importância como um tema que merece mais atenção. A profissão docente é frequentemente mostrada de forma negativa, desvalorizada tanto socialmente, como economicamente, além das condições de trabalho mostradas, onde desmotivam ainda mais jovens a escolherem, como opção acadêmica, cursos de licenciatura.

Visando refletir sobre a carreira docente, estamos desenvolvendo este projeto, por meio do Pibex (Programa Institucional de Bolsas de Extensão), que está conectado a outro Programa de abrangência internacional, o Programa Internacional Despertando Vocação para as Licenciaturas - PDVL. Tal programa, possui um conjunto de atuações que tem como objetivo desenvolver ações que auxiliem no despertar do interesse para os cursos de Licenciatura, através da articulação de atividades de ensino, pesquisa e extensão e da troca de saberes entre a Academia e a Escola Básica, tendo como foco a formação de professores em diversas áreas, entre elas a Geografia.

O projeto tem como campo de atuação uma escola da Rede Pública Estadual, localizada no bairro da Várzea, em Recife. O público alvo são os estudantes e professores de Geografia do Ensino Médio e a áreas temática do projeto apoia-se na Educação Ambiental.

Pretendemos com isso, despertar o interesse dos estudantes do Ensino Médio para o componente curricular Geografia, que geralmente é visto como algo enfadonho, meramente decorativo e distante da realidade vivida. Ao apresentarmos a Geografia como uma ciência que está presente no cotidiano de todos, esperamos também, despertar o interesse para a 
carreira docente.

\section{FUNDAMENTAÇÃO TEÓRICA}

Segundo Zabala (2010), é no ambiente da escola, mediante as relações de construção dos diferentes saberes e experiências que se fundam os vínculos socioafetivos e os momentos que definem as concepções pessoais sobre si e os demais sujeitos. Através disso percebemos que por meio da experimentoteca e explanação em sala, que a atividade despertou, a todo momento, a curiosidade e a reflexão sobre a Geografia, por parte dos alunos. Constituindo essas ações, como importantes na formação do estudante consciente do seu meio e sua função cidadã.

O uso da educação ambiental para atrair olhares dos estudantes do ensino médio é de grande valia, uma vez que provoca a reflexão sobre a realidade e sobre a importância de viver de forma mais harmônica com o espaço no qual está inserido. Em um terreno altamente político e ideológico, a Educação Ambiental surgiu como proposta ao enfrentamento dessa crise através da articulação entre as dimensões social e ambiental (VENTURA e SOUZA, 2010, p.14). Logo, evidenciamos a importância de levar debates acerca do meio ambiente para a escola, que deve ser um espaço de democratização e troca de conhecimentos.

Pretende-se, a partir disso correlacionar os conteúdos da Geografia com a Educação Ambiental, acentuando ainda mais o caráter de interdisciplinaridade e de importância da Geografia, quanto disciplina de formação básica, para a compreensão dos fatos: "O espaço como objeto de análise geográfica não é aquele da experiência empírica, não é um objeto espacial em si mesmo, mas sim uma abstração, uma construção teórica.” (CAVALCANTI, 2008 p. 42).

\section{METODOLOGIA}

O trabalho desenvolveu-se nas seguintes etapas: A primeira foi o Atividades de estudos e revisão de literatura, no Instituto de Educação, Ciência e Tecnologia de Pernambuco (IFPE) em Recife, acerca de temas como ensino e aprendizagem da Geografia, problemas das sociedades urbano-industriais e educação ambiental e também temas relacionados a atratividade pela carreira docente.

A segunda etapa deu-se através das atividades de pesquisa, onde aconteceu o primeiro contato com a escola e professora de geografia, para entender sua visão sobre a educação escolar e alunos, assim foi possível ser direcionado a caminhos para aprimorar a pesquisa. Posteriormente voltamos a escola para realização de roda de diálogos com os estudantes com 
o intuito de melhor entender a turma e seu nível de interesse para a docência, assim como os motivos pelo não interesse.

A última etapa foi a atividade atividades de extensão e ensino, onde foi auxiliada pela aplicação das etapas anteriores, por meio de intervenções didáticas na escola campo, com atividade de ensino da geografia na temática da educação ambiental. Em um primeiro momento, foi realizada uma dinâmica onde recolheu-se para um compartimento com água (que representava um rio), parte do lixo individual de cada aluno, das mochilas, carteiras e outros lugares, com a finalidade de demonstrar o quanto a água que necessitamos para nosso uso pessoal, inclusive para beber, encontra-se poluída. Ao final foi indagado aos alunos se os mesmos teriam coragem de beber aquela água. Em seguida foi reforçado a importância de jogar apenas lixo nas lixeiras, e da reciclagem. Posteriormente, foi realizada uma experimentoteca com uso de garrafas pet e, auxilio dos estudantes para despejar a água no solo sem a cobertura vegetal e em seguida com a cobertura vegetal, para simular a importância da vegetação na preservação do solo, uma vez que compõe importante parte integrada ao meio ambiente, e a vida do homem. Com isso, foi possível simular dois problemas ambiental das cidades, onde se encontra maior contingente promotor de impactos ambiental.

Os estudantes em questão fazem parte da $2^{\circ}$ ano do ensino médio, compondo uma turma de cerca de 25 alunos, onde mostraram-se bastante interessados, quanto a temática abordada.

\section{RESULTADOS E DISCUSSÃO}

A atividade realizada aproximou-se da vida dos alunos, na medida em que levou um problema global (degradação ambiental), muito presente também em escalas menores, inclusive na Região Metropolitana do Recife, onde vivem os estudantes.

Desencadear os processos de compreensão do mundo, considerando o espaço produzido pelos homens ao longo de suas vidas é oportunizar aos alunos a capacidade de se entenderem sujeitos da sua história. (Castrogiovanni,2007, p. 8) Os estudantes perceberam que são agentes ativos e contribuem tanto para a preservação assim como a degradação ambiental. A todo momento foi possível induzir a reflexão e a possibilidade dos alunos pensarem o espaço em que vivem.

Assim, foi possível não apenas ensinar o conteúdo, mas também relacioná-lo a vida dos alunos. As metodologias utilizadas estimularam o entendimento sobre o conteúdo de maneira mais nítida, deixando-o mais interessante, uma vez que está inserido no cotidiano de 
todos. Visto que os problemas ambientais causam preocupações, em escala global, a geografia passa a ser vista pelos estudantes como uma disciplina que denota ainda mais importância, se preocupar com o meio ambiente, que interfere diretamente na vida do homem e se relaciona de forma direta com a vida de cada um.

Uma vez interessados pelos conteúdos da Geografia, surge a eventual possibilidade dos estudantes prestarem vestibular para a licenciatura e, também desmitificam muitos tabus atrelados a disciplina, que geram o problema de escassez pela procura dos cursos.

\section{CONCLUSÕES}

Dada a importância do profissional da educação e, diante de sua desvalorização, o trabalho desenvolvido foi de grande relevância ao subsidiar o desenvolvimento de interesse em estudantes do ensino médio para a componente curricular geografia, onde é possível gerar o contato da academia com a escola e mostrar a disciplina a partir de novas perspectivas metodológicas, afim de apresentar seus conteúdos de forma diferente e mais atrativa.

Indo além, foi possível associar a disciplina com a realidade social dos estudantes e induzir a reflexão em cada participante da atividade, mostrando que a geografia é uma disciplina do dia a dia e como a educação ambiental pode trazer benefícios para a vida de todos.

Programas como o PIBEX são grandiosos para elencar debates e novas percepções de mundo para todos envolvidos. Assim concluímos que as atividades vivenciadas contribuíram na construção do processo de elaboração pessoal dos extensionistas, onde a diversidade dos saberes construídos no contexto das ações pedagógicas da academia com a escola parceira oferece condições de leitura da realidade de forma crítica nas múltiplas visões da ciência geográfica e do contexto educacional e, uma vez que alunos envolvidos nessa atividade entendem sua relevância, em esfera global, todos estarão aptos a conhecer mais a fundo e desenvolver a possível trajetória na careira docente.

\section{REFERÊNCIAS}

CASTROGIOVANNI, Antonio Carlos. Ensino da Geografia: caminhos e encantos. Porto Alegre: EDIPUCRS, 2007

CAVALCANTI, Lana de Souza. A Geografia escolar e a cidade: ensaio sobre o ensino de Geografia para a vida urbana cotidiana. São Paulo: Papirus, 2008.

VENTURA, G., SOUZA, I.C. F. de. Refletindo sobre a relação entre a natureza humana, valores capitalistas e a crise ambiental: contribuições para a promoção da Educação 
A EDUCAÇÃO AMBIENTAL COMO FORMA DE DESPERTAR VOCAÇÕES PARA A CARREIRA DOCENTE

Ambiental Crítica. Revista eletrônica Ambiente e Educação. Rio Grande. v.15. 22p. 13-34. 2010.

ZABALA, Antoni. A prática educativa: como ensinar. Porto Alegre, Artmed: 2010. 